International Journal of Engineering \& Technology, $7(1.2)(2018) 47-52$
International Journal of Engineering \& Technology
WPC
Website: www.sciencepubco.com/index.php/IJET
Research paper

\title{
Mathematical modeling and control of wind energy electric conversion system feeding standalone load
}

\author{
N K Rayaguru ${ }^{1}$, N. Poornachandra Rao ${ }^{2}$, K. Navin Sam ${ }^{3}$, Sunil Kumar Thakur ${ }^{3}$ \\ ${ }^{1}$ Associate Professor, Veltech Multitech Dr.Rangarajan Dr. Sakunthala Engg.College,Chennai \\ ${ }^{2} 2$ Assistant professor, Veltech Dr.RR \& SR University, Chennai \\ ${ }^{3}$ Assistant professor, National Institute of Technology, Puducherry \\ ${ }^{4}$ PG Student, Veltech Dr.RR \& SR University, Chennai \\ *Corresponding author E-mail: kumarrayaguru@veltechmultitech.org
}

\begin{abstract}
In this paper, state space model of the complete Wind Energy Electric Conversion System (WEECS) comprising of wind turbine, Permanent Magnet Synchronous Generator (PMSG), uncontrolled rectifier, DC-DC boost converter, and SPWM inverter feeding a standalone load has been formulated. The derived state space model is then simulated using Matlab/Simulink to test the model. As the standalone three phase load connected to the inverter demands constant output voltage irrespective of intermittent wind pattern, a PI controller is used to control the duty ratio of DC-DC boost converter to maintain constant output voltage at the inverter end.
\end{abstract}

Keywords: WEECS; PMSG; Boost Converter.

\section{Introduction}

In India, electricity supply and demand gap is widening over the years because of increasing load and lack of generation expansion [1]. Hence, to reduce the supply and demand gap, government is planning to expand generation capacity. In view of the rising temperature of the earth due to global warming, generating stations utilizing renewable energy as primary resource are becoming popular [2]. In addition, as most of the people lives in remote areas, the extension of existing transmission network to such areas is economically unviable. So Renewable Electric Energy Conversion Systems (REECS) are becoming popular alternatives to cater the power supply needs of people living in remote areas. Various authors have developed stand-alone REECS using variety of renewable sources to supply isolated loads. In this context, WEECS is found to be one of the good candidates for the stand-alone generating stations. Most of the literature available utilizes induction machine (or) permanent magnet synchronous machine (PMSG) for electricity generation in such WEECS [3]. The merits and demerits of both these electromechanical conversion systems have been detailed in [4].

On one hand, the use of induction machine based WEECS is not suitable for isolated loads. Also it requires an additional capacitor bank which consumes magnetizing reactive power rather than delivering it. In addition, the control of IM based systems is comparatively complex than PMSG based systems. On the other hand PMSG based systems does not require any capacitor bank and also it is easy to control. So, in general IM based systems are preferred for high power capacity grid connected operation and PMSG based systems are preferred for low power capacity isolated operation. In this paper, a $650 \mathrm{~W}$ wind generator is used to supply isolated load and hence PMSG is chosen.

The objective of this paper is to derive a state space model of PMSG driven WEECS feeding standalone load and test the de- rived model using Matlab. In order to maintain constant voltage across the inverter end irrespective of wind speed variation, a closed loop PI controller is used to control the duty ratio of DCDC boost converter. This complete system is simulated using the system dynamic equations.

\section{System configuration}

Fig.1 shows the complete system configuration of a typical PMSG based WEECS feeding an isolated load. The different components of the system are given below:

- Wind turbine

- Permanent magnet synchronous generator (PMSG)

- Uncontrolled rectifier

- DC-DC boost converter

- Three phase voltage source inverter (VSI)

- Three phase load

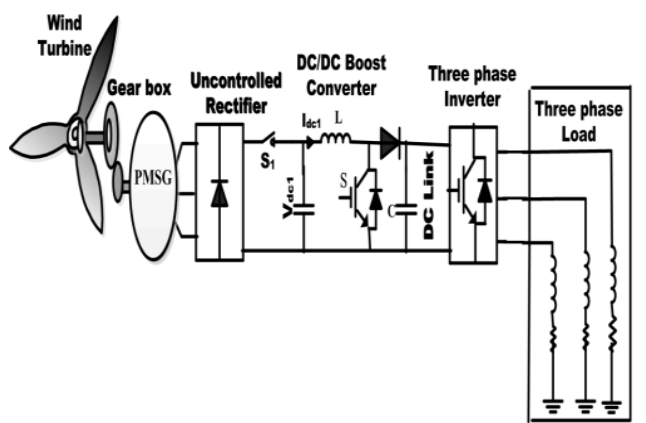

Fig. 1: Configuration of PMSG Based WEECS Feeding Isolated Load.

Wind turbine connected to PMSG generates fluctuating voltage pertaining to intermittent wind pattern. The obtained voltage is 
then rectified using an uncontrolled rectifier. To match to the load requirements, this voltage is then boosted using a DC-DC converter. The primary aim is to maintain the DC link voltage constant by controlling the duty ratio of the DC-DC converter. In order to convert the DC link voltage to required magnitude and frequency of the load voltage and to maintain them constant irrespective of operating conditions, SPWM technique is used to control the three phase inverter.

\section{Mathematical modeling}

Mathematical modelling of all the components including the control strategy will be discussed in the following subsections

\subsection{Wind turbine model}

It is a device that generates mechanical energy when the blades of the turbine rotate as wind passes through them. It converts linear kinetic wind energy into rotational kinetic energy [5]. The power from a wind turbine rotor can be expressed as

$P_{t}=0.5 C_{p}(\lambda) \rho R^{2} v^{3}$

The wind power coefficient $C_{p}$ may be defined as ratio of power output from turbine shaft to the power provided by the wind. The wind power coefficient $C_{p}$ mainly depend upon blade pitch angle, $\beta$ and the tip speed ratio, $\lambda . C_{p}$ can be obtained from the following empirical relationship [6]:

$$
\begin{aligned}
& C_{p}(\lambda, \beta)=0.5176\left(\frac{116}{\lambda_{i}}-0.4 \beta-5\right) e^{\frac{21}{\lambda_{i}}}+0.0068 \lambda \\
& \frac{1}{\lambda_{i}}=\frac{1}{\lambda+0.08 \beta}-\frac{0.35}{\beta^{3}+1}
\end{aligned}
$$

Where the tip speed ratio $\lambda$ is given by

$$
\lambda=\frac{R \omega}{v}
$$

The graph of wind-power coefficient variation with respect to the change in the tip speed ratio at zero blade pitch angle is plotted in the Fig. 2

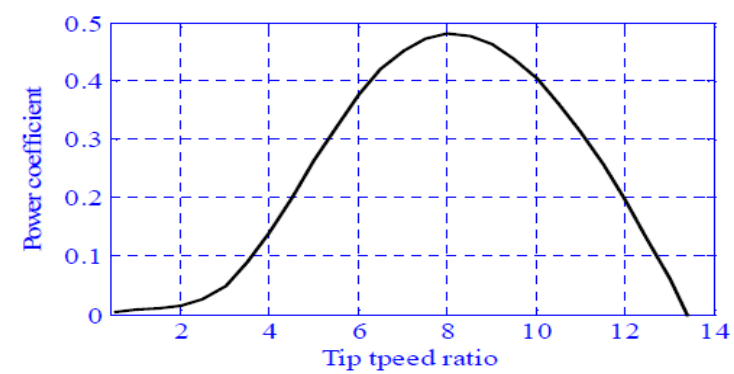

Fig. 2: The Relation between Power Coefficient (Cp) and Tip Speed Ratio $(\Lambda)$ at Zero Blade Pitch-Angle.

\subsection{PMSG model}

In order to develop the mathematical model for a PMSG, it is essential to make the following assumptions [7]

- The conductivity of the permanent magnet is zero.

- Saturation is neglected.

- Induced electromotive force (EMF) is sinusoidal.

- Eddy currents and hysteresis losses are negligible.

- There are no field current dynamics.

The equivalent circuit of PMSG is as shown in the fig. 3

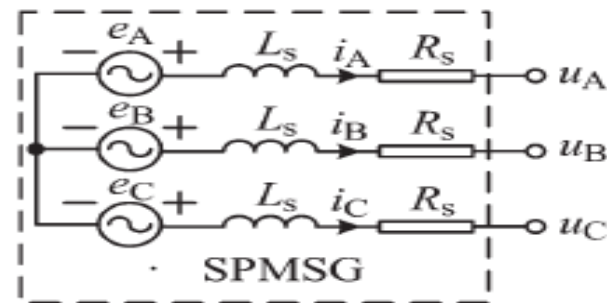

Fig. 3: Equivalent Circuit of PMSG.

The dynamic KVL equations can be written as follows

$u_{A}=-i_{A} R_{s}-L_{s} \frac{d i_{A}}{d t}+\omega_{e} \psi_{P M} \cos \left(\theta_{e}\right)$

$u_{B}=-i_{B} R_{s}-L_{s} \frac{d i_{B}}{d t}+\omega_{e} \psi_{P M} \cos \left(\theta_{e}-\frac{2 \pi}{3}\right)$

$u_{c}=-i_{c} R_{s}-L_{s} \frac{d i_{c}}{d t}+\omega_{e} \psi_{P M} \cos \left(\theta_{e}+\frac{2 \pi}{3}\right)$

After converting the three phase abc dynamic equations into dq form, the equations can be written as

$v_{d}=-R_{s} i_{d}-L_{d} \frac{d i_{d}}{d t}+\omega_{e} L_{q} i_{q}$

$v_{q}=-R_{s} i_{q}-L_{q} \frac{d i_{q}}{d t}-\omega_{e} L_{d} i_{d}+\omega_{e} \lambda_{m}$

In rotor reference frame the electromagnetic torque can be described as

$T_{e}=\frac{3}{2} p_{n} \psi_{P M} i_{q}$

The relationship between the angular velocity of the generator rotor and the mechanical angular velocity of the wind turbine rotor is given as follows

$\omega_{m}=\frac{2 \omega_{e}}{p_{n}}$

The mechanical motion equation of PMSG rotor is given by

$T_{e}=T_{m}-\frac{J}{p_{n}} \frac{d \omega_{e}}{d t}-\frac{F}{p_{n}} \omega_{e}$

\subsection{Uncontrolled rectifier}

The three phase uncontrolled rectifier will convert the generated AC voltage to DC voltage. It is connected between PMSG and DC-DC boost converter. Uncontrolled rectifier has the advantages of simplicity, robustness and low cost while the disadvantages are poor input power factor and distorted DC output voltage [8]. An uncontrolled rectifier consisting of diodes connected in bridge type connection is shown in Fig.4

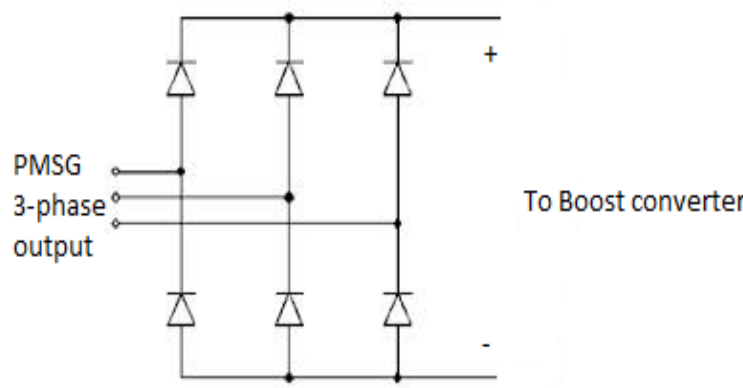

Fig. 4: Uncontrolled Rectifier 


\subsection{DC-DC boost converter}

Although the type of topology with uncontrolled rectifier and controllable inverter is simple and reliable, but the power factor of the generator is low. The other problem is that when the output voltage of the rectifier is lower than the required, power cannot be fed to the load.

A boost converter is used in between diode rectifier and inverter in order to solve the issue of generator power factor. For this topology including boost converter operation at relatively low wind speeds is only possible. The boost circuit can maintain the DC bus link voltage at a constant value. The two operating modes of boost converter is as shown in the Fig.5.

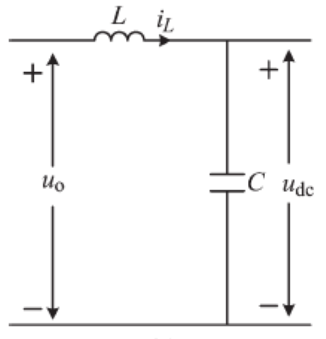

(a)

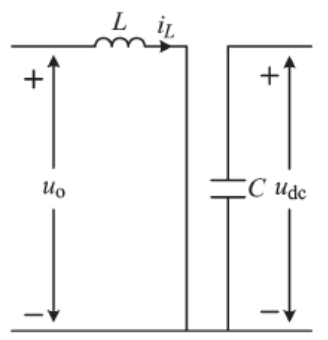

(b)
Fig. 5: Operating Modes of Boost Converter when A) Switch Turned OFF B) Switch Turned ON.

The inductor current iL during turn ON period is given by,

$$
\left(\frac{d i_{L}}{d t}\right)_{O N}=\frac{u_{o}}{L}
$$

During turn OFF period,

$$
\left(\frac{d i_{L}}{d t}\right)_{\text {OFF }}=\frac{u_{o}-u_{d c}}{L}
$$

Therefore average model can be obtained as,

$$
\left(\frac{d i_{L}}{d t}\right)_{\text {avg }}=\left(\frac{d i_{L}}{d t}\right)_{O N}(d T)+\left(\frac{d i_{L}}{d t}\right)_{O F F}(1-d) T
$$

Substituting equations (12) and (13) in (14), we get

$$
\left(\frac{d i_{L}}{d t}\right)_{\text {avg }}=\frac{(1-d) u_{d c}+u_{o}}{L}
$$

Within each electrical cycle of the generator, the diode bridge rectifier has six commutation points. With the commutation process ignored, the interval in which phases A and B are made simultaneously to conduct electricity and the dc-link current flows from phase A to phase B is defined as the AB interval. Similarly, each electrical cycle can be divided into six intervals, namely, $A B$, $\mathrm{AC}, \mathrm{BC}, \mathrm{BA}, \mathrm{CA}$, and $\mathrm{CB}$. Taking the $\mathrm{AB}$ interval as an example, the following equations can be obtained Substituting equations (5) and (6) in (16) we get

$$
\frac{d i_{L}}{d t}=-\frac{2 R_{s}}{2 L_{s}+L} i_{L}-\frac{\sqrt{3} \psi_{P M} \sin \left(\theta_{e}-\frac{\pi}{3}\right)}{2 L_{s}+L} \omega_{e}-\frac{u_{d c}}{2 L_{s}+L}+\frac{u_{d c}}{2 L_{s}+L} d
$$

Equating equations (10) and (12) we get

$$
\frac{d w_{e}}{d t}=\frac{\sqrt{3} \psi_{P M} p_{n}^{2} \sin \left(\theta_{e}-\frac{\pi}{3}\right)}{J} i_{L}-\frac{F}{J} \omega_{e}+\frac{p_{n}}{J} T m
$$

$\frac{d \theta_{e}}{d t}=\omega_{e}$

\subsection{Three phase voltage source inverter}

The load requires three phase constant voltage and constant frequency supply. Hence the DC supply is converted back to AC supply using a three phase inverter. Fig.6 shows the common topology of an inverter

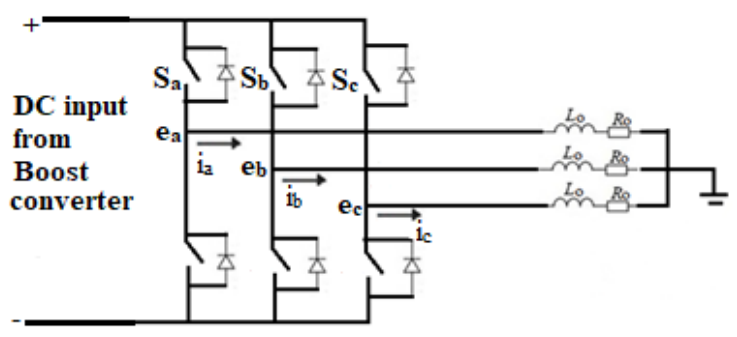

Fig. 6: Three Phase Inverter.

Now, writing the voltage equations in average mode

$$
\begin{aligned}
& \frac{d i_{a}}{d t}=\frac{-R_{0}}{L_{0}} i_{a}-\frac{1}{L_{0}} e_{a}+\frac{u_{d c}}{3 L_{0}}\left(2 S_{a}-S_{b}-S_{c}\right) \\
& \frac{d i_{b}}{d t}=\frac{-R_{0}}{L_{0}} i_{b}-\frac{1}{L_{0}} e_{b}+\frac{u_{d c}}{3 L_{0}}\left(-S_{a}+2 S_{b}-S_{c}\right) \\
& \frac{d i_{c}}{d t}=\frac{-R_{0}}{L_{0}} i_{c}-\frac{1}{L_{0}} e_{c}+\frac{u_{d c}}{3 L_{0}}\left(-S_{a}-S_{b}+2 S_{c}\right) \\
& \frac{d u_{d c}}{d t}=\frac{1}{C} i_{L}-\frac{1}{C}\left(i_{a} S_{a}+i_{b} S_{b}+i_{c} S_{c}\right)
\end{aligned}
$$

Where $\mathrm{Sa}, \mathrm{Sb}, \mathrm{Sc}$ are the duty ratios of switches ea, $e_{b}, e_{c}$ are the 3 phase AC output voltages $\mathrm{i}_{\mathrm{a}}, \mathrm{i}_{\mathrm{b}}, \mathrm{i}_{\mathrm{c}}$ are the load currents

$\mathrm{R}$ is the load resistance

$\mathrm{L}$ is the load inductance

Using d-q transformation,

$$
\left[\begin{array}{l}
i_{d} \\
i_{q}
\end{array}\right]=\frac{2}{3}\left[\begin{array}{ccc}
\sin \left(\theta_{e}\right) & \sin \left(\theta_{e}-\frac{2 \pi}{3}\right) & \sin \left(\theta_{e}+\frac{2 \pi}{3}\right) \\
\cos \left(\theta_{e}\right) & \cos \left(\theta_{e}-\frac{2 \pi}{3}\right) & \cos \left(\theta_{e}+\frac{2 \pi}{3}\right)
\end{array}\right]\left[\begin{array}{l}
i_{A} \\
i_{B} \\
i_{C}
\end{array}\right]
$$

Converting $\mathrm{i}_{\mathrm{a}}, \mathrm{i}_{\mathrm{b}}, \mathrm{i}_{\mathrm{c}}$ to $\mathrm{i}_{\mathrm{d}}, \mathrm{i}_{\mathrm{q}}$

$$
\begin{aligned}
& \frac{d i_{d}}{d t}=-\frac{R_{o}}{L_{o}} i_{d}+\omega i_{q}+\frac{S_{d}}{L_{o}} u_{d c}-\frac{1}{L_{o}} e_{d} \\
& \frac{d i_{q}}{d t}=-\frac{R_{o}}{L_{o}} i_{q}-\omega i_{d}+\frac{S_{q}}{L_{o}} u_{d c}-\frac{1}{L_{o}} e_{q}
\end{aligned}
$$

And the dynamics of the DC link capacitor is given by,

$$
\frac{d u_{d c}}{d t}=-\frac{S_{d}}{C} i_{d}-\frac{S_{q}}{C} i_{q}+\frac{1}{C} i_{L}
$$

\section{State space model of the complete WEECS}

The complete circuit diagram of wind energy electric conversion system (WEECS) is shown in Fig.7 


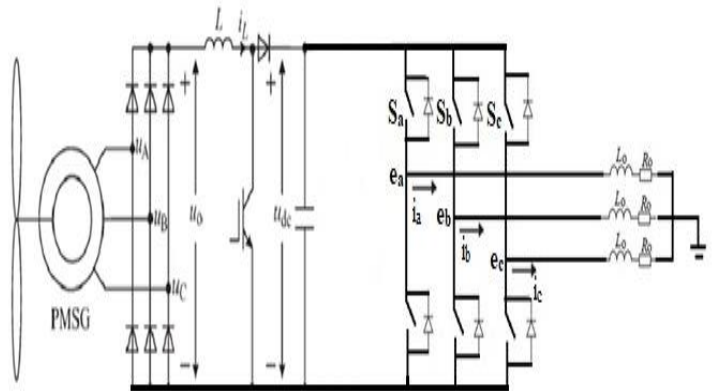

Fig. 7: Circuit Diagram of WEECS.

The state space model of the complete system can be obtained by defining

$\mathrm{x}_{1}=\mathrm{i}_{\mathrm{L}}, \mathrm{x}_{2}=\omega_{\mathrm{e}}, \mathrm{x}_{3}=\left(\theta_{\mathrm{e}}-\pi / 3\right), \mathrm{x}_{4}=\mathrm{i}_{\mathrm{d}}, \mathrm{x}_{5}=\mathrm{i}_{\mathrm{q}}, \mathrm{x}_{6}=\mathrm{u}_{\mathrm{dc}}$ and $\mathrm{u}_{1}=\mathrm{d}, \mathrm{u}_{2}=\mathrm{S}_{\mathrm{d}}$, $\mathrm{u}_{3}=\mathrm{S}_{\mathrm{q}}$

Hence the complete sixth order non-linear system is given by

$$
\begin{aligned}
\dot{X} & =f(X)+g(X) u \\
Y & =h(X)
\end{aligned}
$$

Where

$$
f(X)=\left[\begin{array}{l}
k_{1} x_{1}+k_{2} x_{2} \sin \left(x_{3}\right)+k_{3} x_{6} \\
k_{4} x_{1} \sin \left(x_{3}\right)+k_{5} x_{2}+k_{6} \\
x_{2} \\
k_{7} x_{4}+k_{8} x_{5}+k_{9} x_{6} \\
-k_{10} x_{4}+k_{11} x_{5}+k_{12} x_{6} \\
k_{13} x_{1}+k_{14} x_{4}-k_{15} x_{5}
\end{array}\right] ; g(X)=\left[\begin{array}{ccc}
N_{1} x_{6} & 0 & 0 \\
0 & N_{2} & 0 \\
0 & 0 & N_{3}
\end{array}\right]
$$

$\mathrm{h}(\mathrm{X})=\left[\begin{array}{l}x_{1} \\ x_{2} \\ x_{6}\end{array}\right]$

Where

$k_{1}=-\frac{2 R_{s}}{2 L_{s}+L_{0}}, k_{2}=\frac{-\sqrt{3} \psi_{P M}}{2 L_{s}+L_{0}}, k_{3}=-\frac{1}{2 L_{s}+L_{0}}, k_{4}$

$=\frac{1}{2 L_{S}+L_{0}}, k_{5}=\frac{\sqrt{3} \psi_{P M} p_{n}^{2}}{J}, k_{6}=-\frac{F}{J}, k_{7}=\left(\frac{p_{n}}{J}\right) T_{m}$

$k_{8}=-k_{9}=-k_{10}=\frac{1}{C}, k_{11}=\frac{1}{L}, k_{12}=-\frac{R_{0}}{L}, k_{13}$

$=-\frac{u_{o}}{L}, N_{1}=\frac{1}{2 L_{s}+L_{0}}, N_{2}=N_{3}=\frac{1}{L_{0}}$

As we obtained the above model by considering only one interval AB. As the interval changes the values of $x_{3}$ and $k_{1}, k_{5}$ changes.

\section{Control of output voltage}

The above modelled wind energy electric conversion system produces three phase output voltage depending on the wind pattern As the wind pattern is sporadic in nature, WEECS produces variable output voltage. But the three phase load requires constant voltage. So in order to maintain constant output voltage at the inverter a closed loop control needs to be implemented. So, a proportional integral (PI) controller is used in feed back to control the duty ratio of the DC-DC boost converter in order to maintain constant DC link capacitor voltage. The control structure of the DC-DC boost converter is as shown in Fig.8.

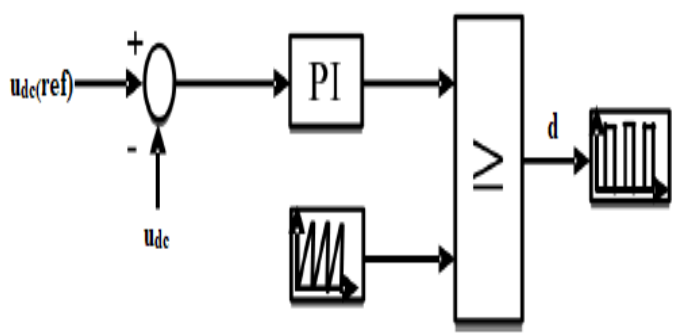

Fig. 8: Control Structure of DC-DC Converter.

The voltage source inverter needs to be controlled to regulate the magnitude of load voltage. To control the inverter out of many techniques available, this paper uses sinusoidal pulse width modulation (SPWM) technique and the relation between DC input voltage and AC output voltage is given by [9].

$V_{\text {line-to-line }}=\sqrt{\frac{3}{2}} \frac{m u_{d c}}{2}$

Where ' $\mathrm{m}$ ' is the modulation index

If the load is balanced, a constant modulation index should be used in order to maintain constant voltage. But in the case of unbalanced load, three different modulation indexes should be used for three phases. Fig.9 shows how to generate pulses for each switch according to modulation index for each phase.

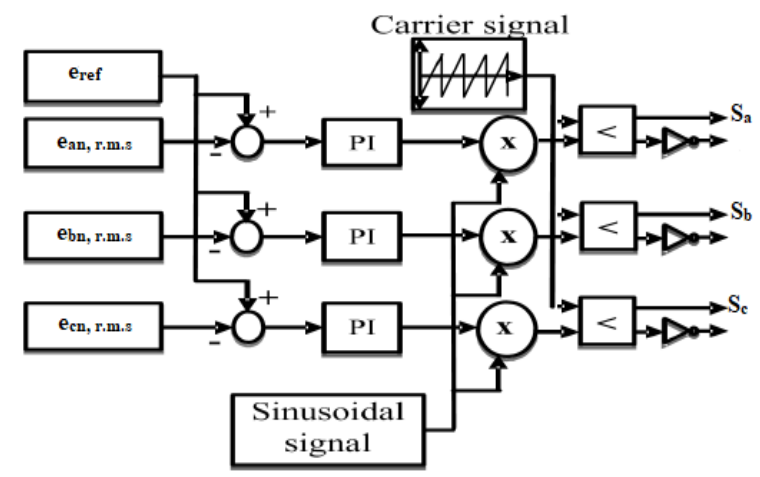

Fig. 9: PWM Generation for Unbalanced Load.

\section{Simulation results}

The proposed system is simulated using state space modelling equations under dynamic conditions. The various results obtained has been furnished in this section

Table 1: Simulation Specifications

\begin{tabular}{lll} 
S.NO & PARAMETER & VALUE \\
\hline 1 & Rated Power & $650 \mathrm{~W}$ \\
2 & Rated Speed & $600 \mathrm{RPM}$ \\
3 & Rated wind Speed & $10.5 \mathrm{~m} / \mathrm{s}$ \\
4 & No.of poles & 10 \\
5 & Stator phase resistance & $0.425 \Omega$ \\
6 & Armature inductance & $0.000835 \mathrm{H}$ \\
7 & Flux linkages & $0.433 \mathrm{wb} / \mathrm{m}^{2}$ \\
8 & Moment of inertia & $0.01197 \mathrm{~kg}-\mathrm{m}^{2}$ \\
9 & Friction Coefficient & 0.001189 \\
10 & DC link voltage & $415 \mathrm{~V}$ \\
\hline
\end{tabular}

\subsection{PMSG Output voltage waveform}

The PMSG output voltage variation for different wind speeds is as shown the figure 10. In figure 10(a) it can be observed that the transient peak voltage rises upto $150 \mathrm{~V}$ when the wind speed is $10.5 \mathrm{~m} / \mathrm{s}$. In fig 10(b) it can be seen the steady state waveform of output voltage. 


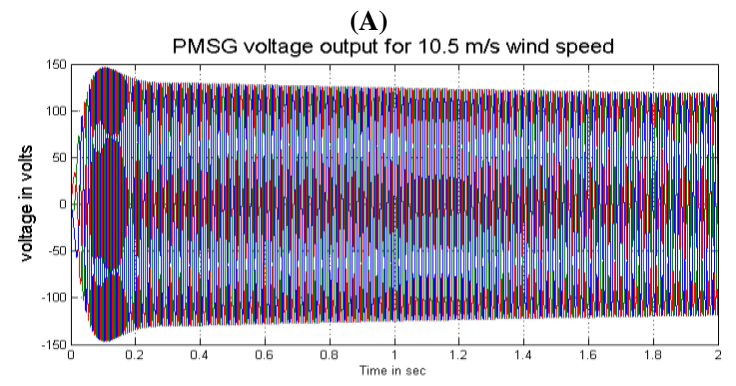

(B)

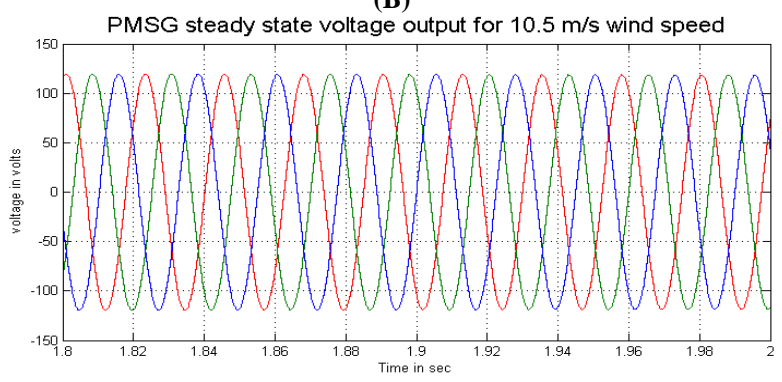

Fig. 10: PMSG Output Voltage for $10.5 \mathrm{M} / \mathrm{S}$ Wind Speed.
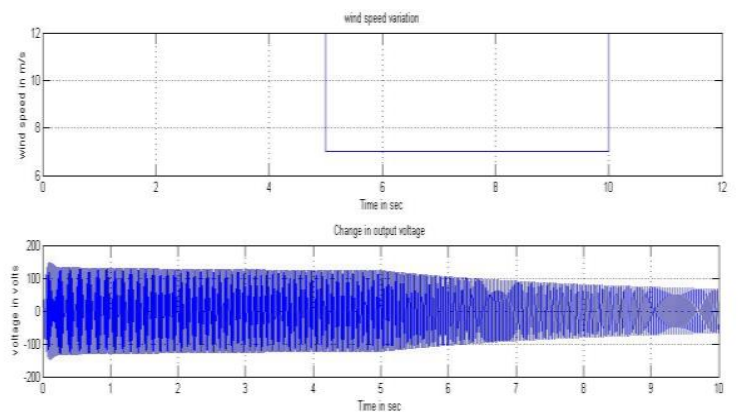

Fig. 11: Wind Velocity Is Changed from $12 \mathrm{M} / \mathrm{S}$ to $7 \mathrm{~m} / \mathrm{S}$ at $\mathrm{T}=5 \mathrm{Sec}$ and 7 $\mathrm{M} / \mathrm{S}$ to $12 \mathrm{M} / \mathrm{S}$ at $\mathrm{T}=10 \mathrm{Sec}$ Respectively.

a) Wind velocity variation b) change in output voltage corresponding to wind velocity

From figure 11 it can be observed that the output voltage variation as the wind velocity varies. When wind velocity is at $12 \mathrm{~m} / \mathrm{s}$ the output voltage is around $100 \mathrm{~V}$ and as the wind velocity changes to $7 \mathrm{~m} / \mathrm{s}$ the output voltage reduces to $60 \mathrm{~V}$. figure 11 (a) shows the wind velocity variation and figure 11(b) shows the corresponding output voltage variation.

\subsection{DC link capacitor voltage waveform}

Fig.12 shows the dynamics of DC link capacitor voltage. It can be observed that the DC link capacitor voltage is maintained constant at $415 \mathrm{~V}$ irrespective of speed variations. This is done by the closed loop PI controller connected in the feedback path of the inverter.

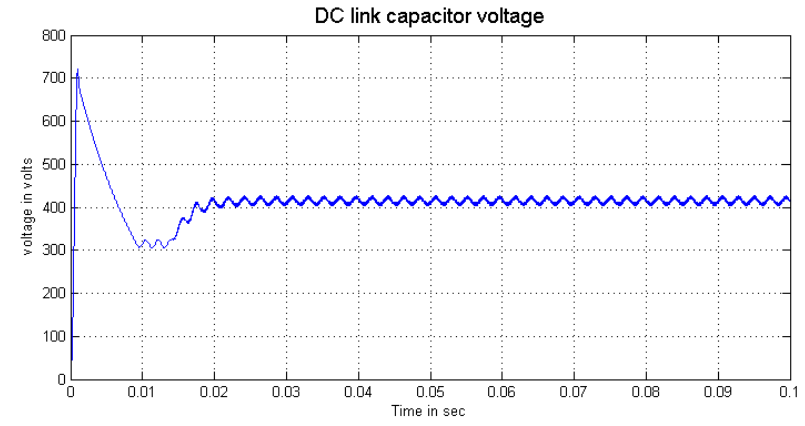

Fig. 12: DC Link Capacitor Voltage Waveform.

\subsection{Inverter output voltage waveforms}

Fig.13 shows the inverter output voltage. It can be observed that the inverter output voltage and frequency is maintained constant independent of load current variation. As the load current is varied from $4 \mathrm{~A}$ to $9 \mathrm{~A}$, the output voltage and frequency are maintained constant.
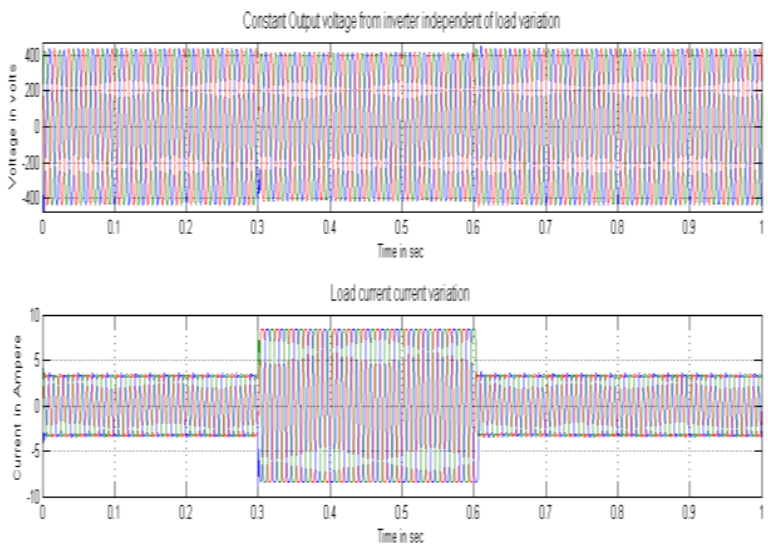

Fig. 13: Step Change in Load from 4 A to $9 \mathrm{~A}$ at $\mathrm{T}=0.3 \mathrm{Sec}$ and from $9 \mathrm{~A}$ to $4 \mathrm{~A}$ at $\mathrm{T}=0.6 \mathrm{Sec}$.

a) Constant output voltage from inverter independent of the load variation

b) Load current variation

From Fig.13 it can be observed that the output voltage of an inverter is maintained constant irrespective of wind velocity variation. Fig 13(a) shows the wind velocity variation from $12 \mathrm{~m} / \mathrm{s}$ to 7 $\mathrm{m} / \mathrm{s}$ at time $\mathrm{t}=1 \mathrm{sec}$ and from $7 \mathrm{~m} / \mathrm{s}$ to $12 \mathrm{~m} / \mathrm{s}$ at time $\mathrm{t}=3 \mathrm{sec}$. Fig.13(b) shows the constant output voltage of the inverter at all times irrespective of wind velocity variation. Fig. 15 gives the steady state output voltage waveform of an inverter. We can observe that the inverter output voltage is maintained constant at 415 $\mathrm{V}$

(A)

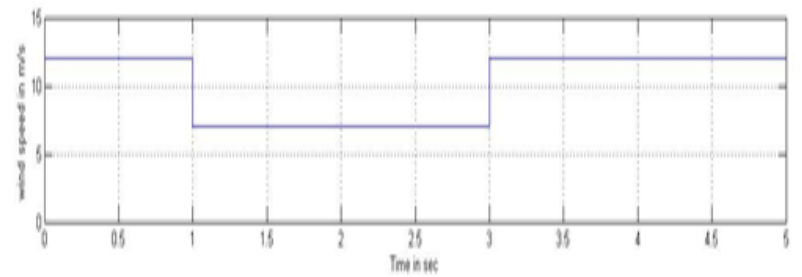

(B)

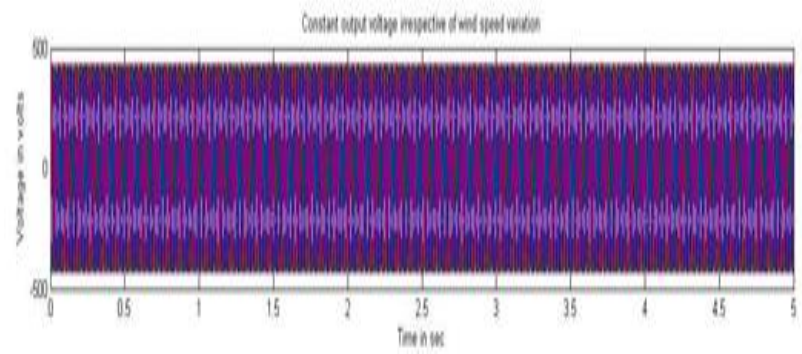

Fig. 14: A) Change in Wind Velocity B) Constant Output Voltage Irrespective of Wind Velocity Variation.

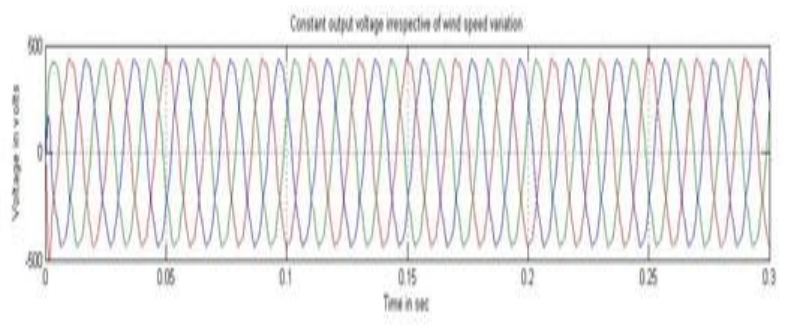

Fig. 15: Steady State Output Voltage of an Inverter. 


\section{Conclusion}

The state space model of WEECS has been formulated and model has been validated using Matlab/Simulink. A PI controlled has been used to control the duty ratio of DC-DC boost converter in order to maintain constant voltage across the inverter end. All the dynamic equations formulated has been validated through Matlab and the results shows that the derived state space model is correct.

\section{References}

[1] Department of power, Government of India "Annual Report 2013 2014".

[2] A.Keane, L.F.Ochoa, C.L.T. Borges,G.W. Ault, A.D. AlarconRodriguez, R.A.F. Currie, F. Pilo, C.Dent and G.P.Harrison, "Stateof-the-Art Techniques and Challenges Ahead for Distributed Generation Planning and Optimization," IEEE Transactions on Power Systems, vol.28, no.2, pp.1493-1502, May 2013. https://doi.org/10.1109/TPWRS.2012.2214406.

[3] H. Ahuja, G. Bhuvaneswari and R. Balasubramanian, "Performance comparison of DFIG and PMSG based WECS," IET Conference on Renewable Power Generation (RPG 2011), Edinburgh, 2011, pp.16. https://doi.org/10.1049/cp.2011.0229.

[4] A. Beainy, C. Maatouk, N. Moubayed and F. Kaddah, "Comparison of different types of generator for wind energy conversion system topologies," 2016 3rd International Conference on Renewable Energies for Developing Countries REDEC), Zouk Mosbeh, 2016, pp. 1-6. https://doi.org/10.1109/REDEC.2016.7577535.

[5] Mukhtiar Singh, Ambrish Chandra, "Control of PMSG Based Variable speed wind Battery Hybrid System in an Isolated Network,"IEEE Trans.Power Delivery, vol. 3, pp. 549-557, Apr. 2009. https://doi.org/10.1109/PES.2009.5275419.

[6] Mohamed Hilmy, Mohamed Orabi, Mahrous E. Ahmed, Mohamed El- Nemr, Mohamed Youssef " A Less Sensor Control Method for Standalone Small Wind Energy Using Permanent Magnet Synchronous Generator,"Twenty-Sixth Annual IEEE Applied Power Electronics Conference and Exposition (APEC)March, 2011, pp.19681974.

[7] L. Barote, C. Marinescu, “PMSG Wind Turbine System for Residential Applications," Proc. of IEEE International Symposium on Power Electronics, Electrical Drives, Automation and Motion, SPEEDAM 2010, 14-16 June, Pisa, Italy, 2010, pp. 772 - 777. https://doi.org/10.1109/SPEEDAM.2010.5542166.

[8] D. A. Khaburi and A. Nazempour, "Design and simulation of a PWM rectifier connected to a PM generator of micro turbine unit," Elsevier, Scientia Iranica, vol. 19, pp. 820-828, 2012 https://doi.org/10.1016/j.scient.2011.09.017.

[9] C. N. Bhende, S. Mishra, Siva Ganesh Malla "Permanent magnet synchronous generator-Based Standalone Wind Energy Supply system," IEEE Trans. Sustainable energy, vol. 2, NO.4, Oct. 2011. 